\title{
Digital Competence of Students from Economic Universities in Vietnam in the Digital Economy
}

\author{
*Anh Duc Do Thi Ngoan Nguyen Xuan Thu Nguyen Hieu Bang Tran Khanh Vy Nguyen Phuong Linh \\ Nguyen \\ School of Trade and International Economics, National Economics University, 207 Giai Phong Street, Hai \\ Ba Trung District, Ha Noi, Vietnam
}

\begin{abstract}
In recent years, digital competence has become one of the most significant fundamental competences in the digital economy. Digital competence is a key aspect for student majoring in economic in order to study and work in the world of the global economy. The development of digital competence for students include the determination of the conceptual content and current status of students' digital competence. For countries conducting digital transformation in the later stages like Vietnam, inheriting the achievements of previous countries is the optimal choice. After analyzing and synthesizing experiences from previous research results and the digital competence measurement frameworks for students from Vietnam and other countries, we chose an appropriate digital competence framework - the DLGF Framework of UNESCO to conduct measurement and assessment of the available digital competences of students. This study will be a basis for proposing the training programs to develop their digital competence for students in Vietnam.
\end{abstract}

Keywords: Digital competence, university students, digital economy.

DOI: $10.7176 / \mathrm{EJBM} / 14-3-02$

Publication date: February $28^{\text {th }} 2022$

\section{Introduction}

The world is gradually transitioning into the digital economy era. The Industrial Revolution 4.0 is vigorously promoting the transition from a resource-based economy to a knowledge-based one with the Internet and digital pillars [Nguyen Hai Hoang, 2020]. The transformation of the digital economy, along with the impact of the COVID-19 pandemic, will cause dramatic dual disruptions in the world of work, the labor market, and the workers [Truong Anh Dung, 2021]. Along with the transition to the digital economy, Vietnam is also in the process of restructuring the labor force, with increasingly growing digital human resources taking the lead in the society's total workforce.

According to UNESCO, digital competence is the ability to safely and appropriately access, administer, understand, combine, communicate, evaluate and create information through digital technology to serve the unskilled and skilled labor market as well as business start-ups. It includes well-known competences, such as computer competence, information technology competence, information competence, or communication competence [UNESCO, 2018]. Statistics show that each country needs a roadmap to identify and assess the current situation and improve the digital competence of its citizens, especially for young people, students, and university students.

When analyzing previous studies on digital competence in Vietnam, we discovered that there is still a scarcity of data on measuring the digital competence of citizens, especially university students. We also noticed the incompleteness, oversimplification, and ambiguity with the concept of digital competence. Above all, though the Vietnamese education system has introduced and implemented a digital learning environment, there is still no data measuring the digital competences of Vietnamese students based on admitted international standards. This study chose the UNESCO DLGF framework (A Global Framework of Reference on Digital Literacy Skills for Indicator 4.4.2) to measure the digital competence of economics students in Vietnam because of its relevance to the economic context as well as the requirements on developing digital competence for human resources in Vietnam nowadays. This study will measure and assess the current level of digital competence among students from economic universities in Vietnam.

The rest of the study is organized as follows: Section 2 shows the literature reviews of research projects on students' digital competence and digital competence frameworks. Section 3 represents a research model and methodology for measuring the current level of digital competence among students from economic universities. Section 4 is the statistical treatment of data and interpretations. Section 5 shows the study's limitations and conclusions are given in Section 6.

\section{Literature review}

\subsection{Overview of research projects on students' digital competence}

\subsubsection{Overview of research projects on students' digital competence in the world}

In 2017, when discussing digital skills at Northern University Bangladesh, a study was conducted on 104 undergraduates and graduates at private universities in Dhaka, Bangladesh. Based on the Report on Basic Digital 
Skills in the UK [Ipsos MORI, 2015], an assessment framework has been devised towards measuring the proficiency of students' digital skills. The results confirmed that Business students need to develop their digital skills, especially in cloud computing, data storage, online trading, business communication, solving problems on digital platforms, and digital content creation.

In 2019, a study at Politehnica University, Romania was conducted to investigate students' perceptions of certain digital skills such as information and data processing, digital communication, digital content creation, and problem-solving with a survey framework built on top of the European DigComp framework. In general, most of the student scores were relatively high. Some aspects were rated lower (building different electronic records; choosing information to share for different purposes; etc.) showed that students were still inexperienced with these skills.

In 2020, researchers at Qingdao University - China conducted a survey, measuring students' digital competence in order to develop a digital competence scale for university students (DC-US). They used the DCUS Digital Competence Framework self-built and developed on an original scale, with 23 categories of digital competence to survey 825 students from two universities in China. Three studies were performed combining the use of factor analysis, Rasch analysis, and the PLS model. Finally, the DC-US digital competence framework was completed with 10 categories and two subscales. That same year, a study measuring digital literacy and assessing the correlation between students' literacies and their overall digital literacy was conducted at a university in Fiji using a newly designed Digital Literacy Scale with a survey of 867 freshmen. The results showed that first-year students had a high numerical ability. The Cronbach's Alpha test also showed that the newly designed digital competence framework was reliable and highly consistent.

In 2021, a study in Spain assessed the technology training level of teaching graduates at the University of Jaen, based on the European Commission's DigComp digital competence framework study. The results showed that the students were mainly self-study, developed a learning style guided by educational institutions, but their way to navigate and collect information was not effective. That same year, research at a university in Malaysia found that digital competence is paramount to society's workforce. $\mathrm{N}$ Khan, S Khan, BC Tan, and CH Loon proposed a digital competence model for students with 10 elements, including Information analysis, Social and communication, Creative, Safe, Problem-solving, Study, Leadership, Security ethics and culture, The business inspiration, Cooperation. Another study in the Czech Republic analyzed and reflected the digital competence of students studying the Bachelor of Library Studies (LIS) Program at Masaryk University to renovate the curriculum and meet the demands of digital competence for librarians. The study used a self-assessment questionnaire based on the DigComp framework. The results showed that the level of competence stability had been relatively high over the years, besides the strongest competence in the fields of information and data, communication and collaboration. Solving technical problems, actively participating in citizenship through digital technology and programming were the most underrated competences; therefore, it indicated that these were the competences that needed improvement.

\subsubsection{Overview of research projects on digital competence of students in Vietnam}

In 2018, a study by the University of Social Sciences and Humanities, Hanoi analyzed information competence based on SCONUL's 7-pillar model and digital competence based on JISC's 7-factor model, which explained the importance of information competence for learners. The initial study provided four basic issues related to the development of training content, including providing a scientific basis for information competence according to an international approach, identifying factors affecting developing information literacy, proposing the basic content/structure of an information literacy program, and demonstrating successful experimentation at a university. It is the basis for universities to inherit and develop information competence training programs for students according to the specific characteristics of their training professions as well as their cultural environment.

In 2019, a study by Nguyen Tan Dai and Marquet P. surveyed the digital literacy of students through four training programs assessed according to AUN-QA in the period 2009 - 2014 in order to build a model to identify the components and criteria for assessing digital literacy at universities in Vietnam. Applying the "semiexploratory analysis" approach, the research results identified a "3-factor, 8-element" model to initially assess the digital capability of Vietnamese students.

In 2021, the research of Tran Duc Hoa and Do Van Hung (University of Social Sciences and Humanities, Hanoi) outlined the context of digital transformation and the need for digital human resources in Vietnam. It compared several digital literacy frameworks are being commonly used in the world today, thereby proposing a digital literacy framework for Vietnamese students with seven competence groups: Equipment and software operation, Information and data literacy, Communicating and collaborating in a digital environment, Digital content creation, Security and safety in cyberspace, Learning and developing digital skills, and career-related digital competences. 


\subsection{Overview of digital competence frameworks}

\subsubsection{Overview of digital competence frameworks in the world}

DigComp 2.0 (2016) and DigComp 2.1 (2017)

The European Commission has launched the Digital Competence Framework DigComp 2.0 and DigComp 2.1 to improve the digital competence of European citizens and support stakeholders to further implement DigComp. DigComp 2.0 identifies key components of digital competence with 4 proficiency levels (beginner, intermediate, advanced, expert) and 5 areas: Information and data literacy, Communication and collaboration, Digital content creation, Safety, and Problem solving. DigComp 2.1 expands to eight more detailed proficiency levels and provides examples of applying those eight levels to the education and employment sectors. This framework has also provided more detail on digital competence proficiency levels to support the development of teaching and learning materials and has also helped in the design of capacity development assessment tools, career guidance and promotion opportunities at work for citizens.

Digital Capability Framework of JISC (2017)

The UK Joint Information Systems Committee (JISC) conducted a study on the digital competence framework for leaders, organization staff, and students in higher and further education. The framework is intended to assist individuals in self-assessment and digital competence development and provide a basis for assessing the current situation, considering strategic direction, and activities to promote the organization's and individuals' reputations. The JISC Framework includes six groups of digital competences: ICT proficiency; Information, media and data literacy; Digital creation, scholarship and innovation; Digital communication, collaboration and participation; Digital learning and personal professional development; Digital identity and wellbeing. JISC has developed a digital competence framework with a broader field of application after adapting from its predecessor.

A Global Framework of Reference on Digital Literacy Skills for Indicator 4.4.2 (2018)

In 2018, UNESCO conducted an empirical study to evaluate 47 digital competence frameworks from economically diverse countries across the remaining continents, compare these frameworks to the European DigComp framework, and conclude that all competences described in these 47 frameworks can be mapped to the DigComp framework [Jashari et al., 2021]. Since then, UNESCO has decided to add a number of skills to the DigComp framework in order to establish the DLGF global reference framework [UNESCO, 2018], including (0) equipment and software operation, (6) DLGF-related competences, and one more ability to think computationally into (5) Problem resolution. UNESCO also developed a road map technique to assist countries, industries, organizations, and individuals in implementing digital literacy strategies and programs.

DQ Framework (2019)

Digital Intelligence Institute (DQ) has developed the DQ Digital Competence Framework to provide a global standard competence framework to help assess the digital competencies of individuals and organizations. The framework includes eight competence groups (with three levels and 24 competences respectively): Digital identity, Digital use, Digital safety, Digital security, Technical emotional intelligence digital, Digital media, Digital literacy, Digital rights. The DQ Framework has been identified as a purpose-fit method for use as the global industry standard for digital skills by the Institute of Electrical and Electronics Engineers (IEEE) program connecting the IEEE digital skills industry. The DQ Framework is used as a general framework for Coalition for Digital Intelligence (CDI) digital literacy, skills, and readiness. In 2019, the DQ framework was updated as part of a collaboration with the Education Framework 2030 of the Organization for Economic Co-operation and Development (OECD) and included a learning-based screening from the best of The top 25 global approaches in the field of digital competences worldwide.

\subsubsection{Overview of digital competence frameworks in Vietnam}

Vietnam has been applying three digital competence frameworks developed by international businesses/organizations: ICDL (International Computer Driving License), IC3 (Digital Literacy Certification), and MOS (Microsoft Office Specialist) framework [UNESCO, 2018]. These frameworks are no longer deemed appropriate for digital competence development in the current context [Bartolomé et al., 2018, 2021] since they mainly focus on describing practice from the grassroots to intermediate level and have not yet demonstrated the cognitively complex operations of digital competence. Furthermore, these descriptions are tool-oriented only, and specifically focus on desktop and laptop operations while $65 \%$ of 16 -year-olds now tend to use mobile devices to connect to the Internet [Eurostat, 2017]. Vietnam has developed a set of IT skill standards that apply to all agencies, companies, and persons who are directly involved in or related to the assessment of IT skills in the country based on the three digital competence frameworks mentioned above. This set of standards consists of two levels: basic level includes 06 modules coded from IU01 to IU06, advanced level includes 09 modules coded from IU07 to IU15 [Ministry of Information and Communication, 2014].

\section{Methodology}

\subsection{Research model and variables}

This study aims to validate the model structure for measuring the digital competence of students from six economic 
universities in Vietnam.

The study considered seven different variables adopted from the UNESCO framework to measure the students' overall digital competence. Thus the predicted variables include - Hardware and software operation (HSO), Information and Data Literacy (IDL), Communication and Collaboration (CC), Digital content creation (DCC), Safety (SA), Problem Solving (PS), and Career-related competences (CRC). The conceptual framework of the study is illustrated in Figure 1. In addition, the study looked at four demographic variables: gender, education level, university, and field of study.

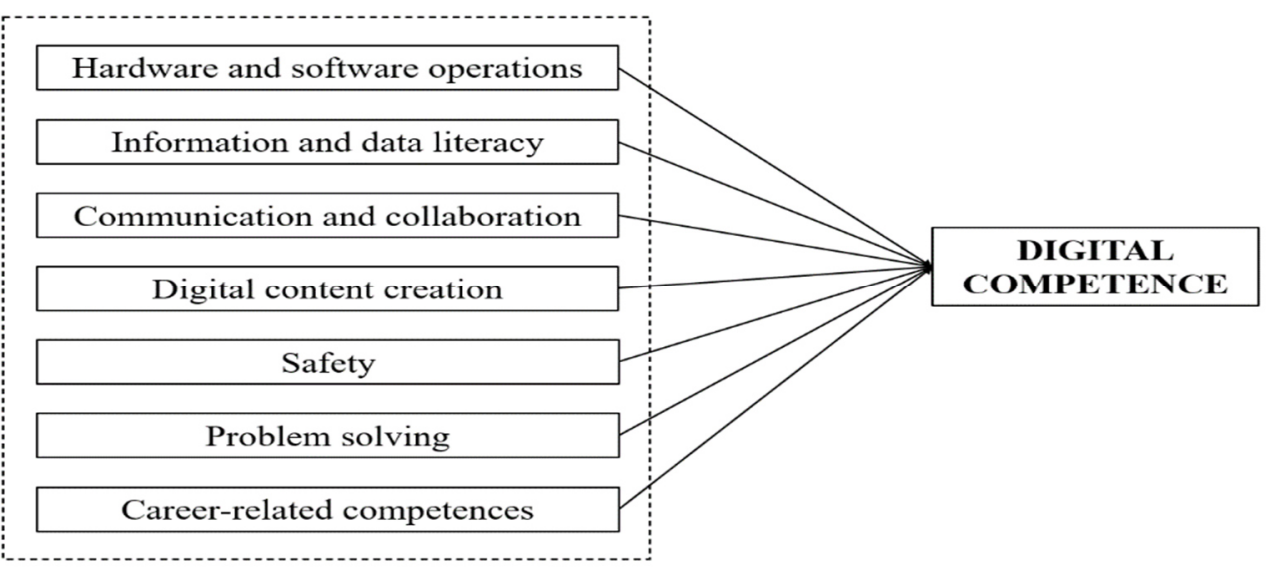

Figure 1: Research Model

Hardware and software operation (HSO) refers to the extent an individual is able to operate tools and technology; identify, utilize physical tools and technology that recognize data, information, and digital material.

Digital Information \& Data Capacity (DID) refers to the extent an individual is able to clarify information requirements, find and access data, information, and digital material; examine the sources of news and their content.

Communication and Collaboration (CC) refers to the extent an individual is able to engage, communicate, and cooperate using digital technology while being aware of cultural and generational differences; social interaction through public and private digital services and civic activity; management of user digital identity and reputation.

Digital content creation (DCC) refers to the extent an individual is able to make and modify digital material; update, combine information and digital content into existing knowledge as well as comprehend appropriate permissions and copyrights; understand how to provide simple commands to a computer system.

Safety $(\boldsymbol{S A})$ refers to the extent an individual is able to protect devices, personal data and privacy in the digital environment; protect health and spirit; awareness of the impact of digital technology on social well-being and social inclusion; awareness of the impact of technologies and their use on the environment.

Problem Solving (PS) refers to the extent an individual is able to solve device and internet problems confidently. Career-related competences $(\boldsymbol{C R C})$ refers to the extent an individual is able to create digital contents.

\subsection{Sampling, Data Collection and Analysis}

The study sample has randomly selected students from six economic universities of Ha Noi, Viet Nam. A formal questionnaire with 71 statements, including the questions on demographic characteristics, has been designed. Statements were delivered to 3584 undergraduates (3576 responses were chosen and 8 completed questionnaires were deleted owing to answer mistakes). Hence, the survey response rate is about 99.7 percent. The students were asked to evaluate and score their degree of digital abilities using the questionnaire's pre-selected criteria. The 71 statements were scored on a 5-point Likert scale to determine the respondents' opinions.

Data were examined using SPSS software to see whether the factors have any link with one another and whether the variables have a significant influence on gauging an individual's digital abilities or not. As a result, Pearson's correlation has been used [Evans, J. D. (1996)]. Additionally, descriptive statistics for each variable were computed to determine which specific digital application the participants had skill in, so that the mean and standard deviations have been computed. Furthermore, the study seeks to assess data reliability and sphericity, Cronbach's Alpha has been used to investigate the internal consistency and sampling adequacy of each variable [Cronbach, L. J. (1951)].

\section{Statical treatment of data and interpretations}

\subsection{Respondent profile}

The survey recorded 3576 valid responses, including 445 votes $(12.44 \%)$ from males, 3125 votes $(87.38 \%)$ from females and six votes $(0.16 \%)$ from other genders. Third-year students garnered the most votes, with $1323(37 \%)$, 
followed by freshmen with 1034 (28.9\%), sophomores with 789 (22.1\%), fourth-year students with 409 (11.4\%), and fifth-year students with 21 votes $(0.6 \%)$. As a result of this survey, it is reasonable to conclude that third-year students have more concern about this survey.

Table 1 shows the number and percentage of students participating in the survey from the Northern economic schools in Vietnam, mainly the VNU University of Economics and Business, National Economics University, Thuongmai University, Banking Academy, and Vietnam Academy of Finance.

Table 1: Respondent of students from economic universities in Vietnam

\begin{tabular}{|c|c|c|}
\hline University & Undergraduate & Percentage \\
\hline VNU University of Economics and Business & 341 & 9,5 \\
\hline National Economics University & 1100 & 30,8 \\
\hline Foreign Trade University & 550 & 15,4 \\
\hline Thuong Mai University & 150 & 4,2 \\
\hline Banking Academy & 548 & 15,3 \\
\hline Academy of Finance & 687 & 19,2 \\
\hline Other Universities & 200 & 5,6 \\
\hline
\end{tabular}

\subsection{Descriptive statistics analysis}

According to the data from Table 2, the average index of Group 0 - Hardware and software operation (HSO) - is $3.63(\mathrm{SD}=0.946)$. All aspects are rated above 3.63, except for an understanding of the overall computer components, the ability to use advanced keyboard shortcuts and set up settings, and updating applications, software, and technical equipment scores lower than the group's average index. Thus, students can use basic digital software quite proficiently. However, for aspects that require a high level of digital competence, economics students respond with more modest results.

Table 2: Descriptive Statistic On Devices and Software Operations Competence

\begin{tabular}{|l|c|c|}
\hline \multicolumn{1}{|c|}{ Competences } & Mean & SD \\
\hline Physical operations of digital devices & 3,625 & 0,953 \\
\hline Software operations in digital devices & 3,634 & 0,939 \\
\hline Total & 3,63 & 0,946 \\
\hline
\end{tabular}

Table 3 shows the average index of Group 1 - Digital Information \& Data Capacity (DID) - is 3,435 $(\mathrm{SD}=1,076)$. Competences related to browsing, searching, and filtering data, information, and digital content scores well below the group's average index. Thus, students only use simple data search operations. Evaluating data and storing information are two aspects that score higher than the average index of this group. It shows that students can systematically manage and store digital information as well as pay attention to the reliability of the information.

Table 3: Descriptive Statistic On Information and Data Literacy Competence

\begin{tabular}{|l|c|c|}
\hline \multicolumn{1}{|c|}{ Competences } & Mean & SD \\
\hline Browsing, searching and filtering data, information and digital content & 3,103 & 1,133 \\
\hline Evaluating data, information and digital content & 3,88 & 0,996 \\
\hline Managing data, information and digital content & 3,323 & 1,046 \\
\hline Total & 3,435 & 1,058 \\
\hline
\end{tabular}

Table 4 illustrates the average index of Group 2 - Communication and Collaboration $(\mathrm{CC})$ is $3.92(\mathrm{SD}=0.902)$. Interaction, information sharing, and social communication through digital technology score relatively high. In general, students majoring in economics could proficiently and diversely use digital tools in the process of studying and working. However, several other competences related to citizenship, collaboration, and digital identity management are below average. This shows that students need to improve their digital competences. 
Table 4: Descriptive Statistic On Communication and Collaboration

\begin{tabular}{|l|c|c|}
\hline \multicolumn{1}{|c|}{ Competences } & Mean & SD \\
\hline Interacting through digital technologies & 4,12 & 0,849 \\
\hline Sharing through digital technologies & 4,19 & 0,837 \\
\hline Engaging in citizenship through digital technologies & 3,72 & 0,932 \\
\hline Collaborating through digital technologies & 3,695 & 0,945 \\
\hline Netiquette & 4,01 & 0,884 \\
\hline Managing digital identity & 3,78 & 0,962 \\
\hline Total & 3,92 & 0,902 \\
\hline
\end{tabular}

According to data from Table 5, the average index of Group 3 - Digital content creation (DCC) - is 3.374 $(\mathrm{SD}=0.979)$. Developing digital content; Integrating and re-elaborating digital content; Copyright and licenses are both appreciated. In particular, the competences related to the creation of publications and videos have lower values of means than those of text, sheets, presentations, etc. Besides, programming has the lowest average results, which can be seen that economics students are less interested in programming.

Table 5: Descriptive Statistic On Digital Content Creation

\begin{tabular}{|l|c|c|}
\hline \multicolumn{1}{|c|}{ Competences } & Mean & SD \\
\hline Developing digital content & 3,74 & 0,917 \\
\hline Integrating and re-elaborating digital content & 3,584 & 0,982 \\
\hline Copyright and licenses & 3,79 & 0,925 \\
\hline Programming & 2,383 & 1,09 \\
\hline Total & 3,374 & 0,979 \\
\hline
\end{tabular}

Table 6 represents the descriptive statistics of Group 4 - Safety (SA) in which the average index is 3.6 $(\mathrm{SD}=1.002)$. The results show that economics students have a sense of environmental and data protection but have not yet identified all risks on digital platforms. The ability to distinguish suitable content when sharing information is quite high, while the ability to relate to personal data security and privacy is relatively low. Besides, the balance between using technology and ensuring health is still a dilemma for Vietnamese students.

Table 6: Descriptive Statistic On Safety

\begin{tabular}{|l|c|c|}
\hline \multicolumn{1}{|c|}{ Competences } & Mean & SD \\
\hline Protecting devices & 3,55 & 1,043 \\
\hline Protecting personal data and privacy & 3,55 & 1,021 \\
\hline Protecting health and well-being & 3,623 & 0,961 \\
\hline Protecting the environment & 3,675 & 0,983 \\
\hline Total & 3,6 & 1,002 \\
\hline
\end{tabular}

Table 7 shows the descriptive statistics of Group 5 - Problem Solving (PS) in which the average index is 3.21 $(\mathrm{SD}=1,016)$, making it one of the lowest score groups. Such scores are influenced by abilities related to Solving technical problems and Computational thinking. It indicates that economics students are patient when encountering technical problems, but are limited in solving those problems. In addition, most students have some difficulties in using digital technology to solve computational problems.

Table7: Descriptive Statistic On Problem-solving

\begin{tabular}{|l|c|c|}
\hline \multicolumn{1}{|c|}{ Competences } & Mean & SD \\
\hline Solving technical problems & 3,11 & 1,029 \\
\hline Identifying needs and technological responses & 3,41 & 0,993 \\
\hline Creatively using digital technologies & 3,285 & 0,989 \\
\hline Identifying digital competence gaps & 3,443 & 0,987 \\
\hline Computational thinking & 2,78 & 1,08 \\
\hline Total & 3,21 & 1,016 \\
\hline
\end{tabular}

According to the data from Table 8, the average index of Group 6 - Career-related competences (CRC) - is $3.22(\mathrm{SD}=1.128)$. Along with Group 5, this is one of the two lowest score groups. It indicates that the surveyed 
students have a certain understanding and ability to use digital devices and specialized software to handle tasks related to their field of study. However, the results are not high so that they need to pay attention in learning more about digital software to meet the needs of the current digital transformation era. The scores obtained in two aspects of group 6.2 are less than 3.21, showing that students need to learn more to improve their proficiency in intensive operations skills when using software related to their field of study to improve their learning and working performance.

Table 8: Descriptive Statistic On Career-related Competences

\begin{tabular}{|l|c|c|}
\hline \multicolumn{1}{|c|}{ Competences } & Mean & SD \\
\hline Operating specialized digital technologies for a particular field & 3,235 & 1,151 \\
\hline Interpreting and manipulating data, information and digital content for a particular field & 3,203 & 1,105 \\
\hline Total & 3,22 & 1,128 \\
\hline
\end{tabular}

\subsection{Test of data reliability}

The SPSS 26 software was used to process 3576 valid replies in the group's study. Cronbach's Alpha and Corrected Item - Total Correlation were used to evaluate if the scales in each factor could show the features and attributes of the factor. The results of evaluating the scale of the independent variables are shown in Table 9 below.

SCALE RELIABILITY ANALYSIS $(\mathbf{n}=3576)$

\begin{tabular}{|c|c|c|c|c|}
\hline \multirow[t]{2}{*}{ Variable } & \multicolumn{2}{|c|}{$\begin{array}{c}\text { Number of } \\
\text { observed variables }\end{array}$} & \multirow{2}{*}{$\begin{array}{c}\text { Cronbach's } \\
\text { Alpha } \\
\end{array}$} & \multirow[t]{2}{*}{$\begin{array}{l}\text { Smallest Corrected } \\
\text { Item-Total Correlation }\end{array}$} \\
\hline & Before & After & & \\
\hline Devices and software operations & 7 & 7 & 0,806 & 0,394 \\
\hline Information and data literacy & 7 & 7 & 0,854 & 0,48 \\
\hline Communication and collaboration & 11 & 11 & 0,92 & 0,605 \\
\hline Digital content creation & 14 & 14 & 0,887 & 0,388 \\
\hline Safety & 14 & 14 & 0,932 & 0,549 \\
\hline Problem-solving & 13 & 13 & 0,928 & 0,582 \\
\hline Career-related competences & 5 & 5 & 0,898 & 0,677 \\
\hline
\end{tabular}

Seven latent variables and 71 observable variables are used to illustrate economics students' digital competence in the context of the digital economy in Vietnam. The Cronbach's Alpha coefficient of the variables was found to be in the range of 0.806 to 0.932 , which is good $(>0.6)$. A level greater than 0.8 in all confidence coefficients indicates that the scale is relatively reliable. This study did not eliminate any of the 71 observed variables because they all had a total correlation coefficient larger than 0.3 .

\subsection{Analysis of correlations}

In this study, the table below shows the correlation between the independent variables. According to the correlation matrix, all variables were positively related at a $99 \%$ level of significance. This means that model variables, including Hardware and software operation (HSO), Digital Information \& Data Capacity (DID), Communication and Collaboration (CC), Digital content creation (DCC), Safety (SA), Problem Solving (PS), Career-related competences $(\mathrm{CRC})$ were all positively correlated. According to the correlation study results, the relationship between competence groups was stronger when the Pearson coefficients were greater than 0.6 , while other values showed a moderate correlation.

CORRELATIONS MATRIX AMONG MODEL VARIABLES (n=3576)
\begin{tabular}{|l|r|r|l|l|l|l|l|}
\hline & HSO & DID & CC & DCC & SA & PS & CRC \\
\hline HSO & 1 & & & & & & \\
\hline DID & $.581^{* *}$ & 1 & & & & & \\
\hline CC & $.594^{* *}$ & $.437 * *$ & 1 & & & & \\
\hline DCC & $.669^{* *}$ & $.601 * *$ & $.663^{* *}$ & 1 & & & \\
\hline SA & $.528^{* *}$ & $.515^{* *}$ & $.658^{* *}$ & $.664^{* *}$ & 1 & & \\
\hline PS & $.557^{* *}$ & $.604^{* *}$ & $.563^{* *}$ & $.716^{* *}$ & $.740^{* *}$ & 1 & \\
\hline CRC & $.370^{* *}$ & $.610^{* *}$ & $.279^{* *}$ & $.526^{* *}$ & $.442^{* *}$ & $.601^{* *}$ & \\
\hline
\end{tabular}




\section{Limitations of the study}

This study uses the UNESCO DLGF Framework to measure the digital competence of students majoring in Economics in Vietnam. Although the DLGF framework has added several digital competence areas, detailed instructions on how to use it, as well as publications on practical use, have not been found yet. In addition, the study only stopped at measuring the actual status of students' digital capabilities, but did not measure the level of digital competence needed to meet the requirements of the labor market. Besides, the survey sample collected is not equal in quantity between universities and is limited to the economic sectors. However, the study could be further expanded when considering these factors in the future.

\section{Conclusions}

In general, most students of economics majors in Vietnam rate their digital competences as above average. However, they still need to develop digital competencies to meet the requirements of the digital economy, especially for problem-solving and career-related competences. In addition, students lack experience in aspects such as computational thinking, programming, etc. Since then, students urgently need specific programs to improve digital competence in order to reduce the gap between the level of current digital competence and the level of digital competence required for the digital economy. In Vietnam, digital technology will soon replace traditional jobs; therefore, acquiring and developing digital competence is indispensable for students of the economics major to compete in the workplace. Thus, our research has given an overview of the current digital competences of economics students in Vietnam. Our research is the basis for universities to consult and create digital competence training programs for students according to their own specific training professions as well as their own cultural environment.

\section{References}

Araújo-Vila, N., Cardoso, L., Toubes, D. R., \& Fraiz-Brea, J. A. (2020). Digital Competence in Spanish University Education and Its Use by Students. Publications, 8(4), 47.

Bartolomé, J., Garaizar, P., \& Larrucea, X. (2021). A Pragmatic Approach for Evaluating and Accrediting Digital Competence of Digital Profiles: A Case Study of Entrepreneurs and Remote Workers. Technology, Knowledge and Learning, 1-36.

Bartolomé, J., de Soria, I. M., Jakobsone, M., Fernández, A., Ruseva, G., Koutoudis, P., ... \& Vaquero, M. (2018, March). Developing a digital competence assessment and accreditation platform for digital profiles. In Proceedings of the 12th International Technology, Education and Development Conference (INTED), Valencia, Spain (pp. 5-7).

Carretero Gomez, S., Vuorikari, R. and Punie, Y., DigComp 2.1: The Digital Competence Framework for Citizens with eight proficiency levels and examples of use, EUR $28558 \mathrm{EN}$, Publications Office of the European Union, Luxembourg, 2017, ISBN 978-92-79-68006-9 (pdf),978-92-79-68005-2 (print),978-92-79-74173-9 (ePub), doi:10.2760/38842 (online),10.2760/836968 (print),10.2760/00963 (ePub), JRC106281.

Cerny, M. (2021). Digital Competences of Students of Library Studies: Comparison of Research Results for 20182020. Education Sciences, 11(11), 729.

Chowdhury, S. M. R., Azhar, A., \& Tarannum, T. (2017, September). Factors Measuring Digital Skills of Business Students: Empirical Evidence from Private Universities of Dhaka, Bangladesh. In Welcome Message from Conference Chairs (Vol. 12, No. 6.9, p. 42).

Cronbach, L. J. (1951). Coefficient alpha and the internal structure of tests. Psychometrika, 16, 297-334.

Do, V.H, Le, T.N, \& Nguyen, B.T. (2018). Developing training program on information literacy for students in the digital era. Journal of Information and Documentation, (3), 9.

Evans, J. D. (1996). Straightforward Statistics for the Behavioral Sciences. Pacific Grove, CA: Brooks/Cole Publishing.

Eurostat. (2017). Digital economy and society statistics - households and individuals.

GO ON UK, Ipsos MORI. (2015). Basic Digital Skills: UK Report. UK.

Khan, N., Khan, S., Tan, B. C., \& Loon, C. H. (2021, February). Driving Digital Competency Model Towards IR 4.0 In Malaysia. In Journal of Physics: Conference Series (Vol. 1793, No. 1, p. 012049). IOP Publishing.

Law, N., Woo, D., de la Torre, J., \& Wong, G. (2018). A global framework of reference on digital literacy skills for indicator 4.4. 2. Unesco Institute for Statistics.

Ministry of Information and Communications. (2014). The Circular prescribes standards of skills in using information technology. No. 03/2014/TT-BTTTT.

Nguyen, T.D., \& Marquet, P. (2019). The digital capability of students for social needs: Research on a preliminary applied model in Vietnam. Review of Social Sciences Ho Chi Minh City, 249(5), 24-38.

Nguyen, H.H. (2022). Developing digital human resources to meet the requirements of the digital economy (2022). Retrieved 21 January 2022, from https://tcnn.vn/news/detail/48102/phat-trien-nguon-nhan-luc-so-dap-ungyeu-cau-cua-kinh-te-so.html. 
Park, Y. (2019). DQ Global Standards Report 2019: Common Framework for Digital Literacy, Skills and Readiness. DQ Institute.

Pérez-Navío, E., Ocaña-Moral, M. T., \& Martínez-Serrano, M. D. C. (2021). University Graduate Students and Digital Competence: Are Future Secondary School Teachers Digitally Competent?. Sustainability, 13(15), 8519.

Reddy, P., Sharma, B. N., \& Chaudhary, K. C. (2020, June). Measuring the digital competency of freshmen at a higher education institute. In the Pacific Asia Conference on Information Systems Proceedings. Association for Information Systems.

Tran, D. H., \& Do, V. H. (2021). Digital literacy framework for Vietnam students in the digital transformation. Journal of Information and Documentation.

UNESCO. (2018). A Global Framework of Reference on Digital Literacy. In Information Paper (Vol. 51, Issue 51, pp. 1-146).

Vuorikari R, Punie Y, Carretero Gomez S and Van Den Brande G. DigComp 2.0: The Digital Competence Framework for Citizens. Update Phase 1: the Conceptual Reference Model. EUR 27948 EN. Luxembourg (Luxembourg): Publications Office of the European Union; 2016. JRC101254.

Wang, X., Wang, Z., Wang, Q., Chen, W., \& Pi, Z. (2021). Supporting digitally enhanced learning through measurement in higher education: Development and validation of a university students' digital competence scale. Journal of Computer Assisted Learning. 